

\section{Constructing a Flexible Model of Integrated Professional Practice Part 3 - The Model in Practice}

\section{Word Count}

5,550 words (excluding abstract, tables and references)

6,874 including abstract, tables and references

\section{Authors}

Gillian Rhydderch - Academic Director, DEdPsy Professional Training Programme, School of Psychology, Cardiff University and Educational Psychologist, City and County Borough of Swansea.

John Gameson - Professional Director, DEdPsy Professional Training Programme, School of Psychology, Cardiff University and Senior Educational Psychologist, Blaenau Gwent County Borough Council.

\section{Address for Correspondence}

Gillian Rhydderch, School of Psychology, Cardiff University, Tower Building, Park Place, Cardiff, CF10 3AT, Wales, UK.

Tel: $\quad+44(0) 2920874007$

Fax: $\quad+44(0) 2920874858$

E-mail: RhydderchGA@Cardiff.ac.uk 


\section{Constructing a Flexible Model of Integrated Professional Practice \\ Part 3 - The Model in Practice}

\section{Abstract}

This is the third in a series of three papers that has introduced the Constructionist Model of Informed Reasoned Action (COMOIRA). The first two papers articulated the theoretical and conceptual issues underpinning the model and explored some important process and practice issues associated with it.

Initially, this paper will discuss two important concepts that contextualise the model. Firstly, that the model was, and is, in an ongoing process of development, and, secondly, that the model is a heuristic, providing a template to guide the professional work of an applied psychologist, rather than a prescriptive process in which actions must follow in a particular, unchanging order.

This third paper then illustrates some applications of the model in working with individuals and groups within the Cardiff University training programme for educational psychologists (EPs) and also in the work of the authors with service users, including joint work at an organisational level with one educational psychology service (EPS). Moving from a theoretical perspective to a practical, day-to-day application of any model, or even simply contemplating such a move, inevitably generates challenges for individuals and organisations and these are discussed from a constructionist perspective. This section also addresses some complex issues and tensions associated with the idea of providing detailed worked examples of the model in practice, 
especially when there are expectations and assumptions that doing so will be inevitably positive and helpful.

Whilst the model has been exported from the training programme and has been taken up in a variety of ways by some individual EPs and some EPSs, there is a need to explore more systematically its impact and value beyond the context of the training programme. The next phase of development will involve monitoring and evaluating the usefulness of the model to colleagues in the field, and will include investigating the use of the model by EPs accustomed to using it previously as trainees on the Cardiff programme. When investigating and evaluating how the model has been used and viewed by individual EPs, however, it will be critical also to explore the contextual and systemic factors that might encourage, enable and support the use of a new model, as well as those that might discourage, oppose and/or inhibit its application and development. 
COMOIRA, change and the EP profession personalised etc.

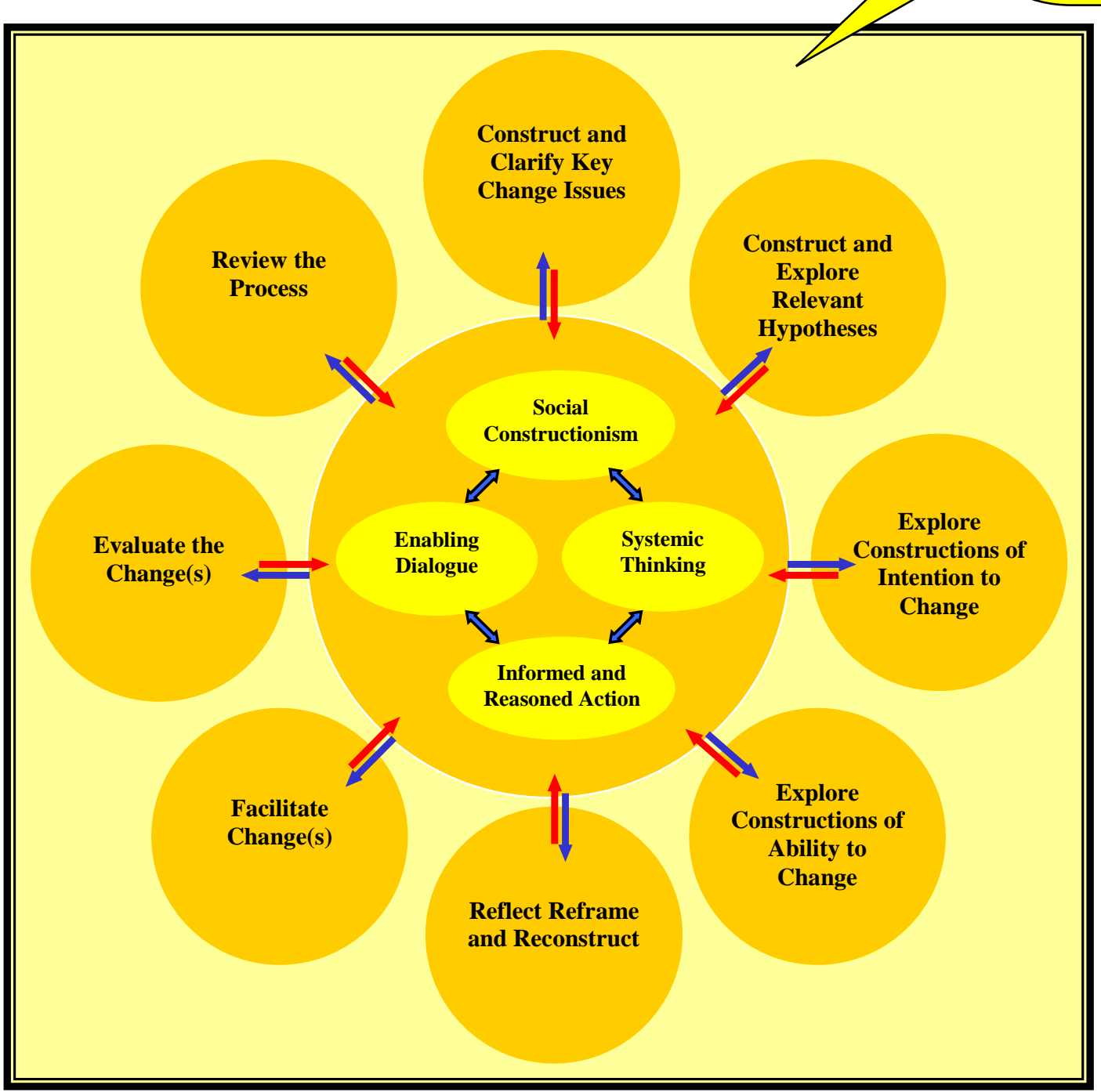

Boyle and MacKay (2007) report that (based on a survey of head teachers in 112 primary and 24 secondary schools in four education authorities in

Scotland, initially surveyed in 1994), in Scotland at least, there have been recent changes in EP practice and in schools' expectations of EPs, with more involvement of EPs at a strategic level in both types of schools and in research and development in primary schools. As Boyle and MacKay note, "All of these developments indicate a predictable progression in the 
reconstruction of educational psychology in terms of the processes of educational change..." (p.23).

COMOIRA encapsulates and encourages this idea of reconstruction, with its explicit focus on processes that examine and promote change at the individual, group, systems or organisational level. COMOIRA itself can be adopted and used at all of these levels in an infinite variety of ways, some of which are illustrated in a later section of this paper.

O'Hanlon (2006) describes how he wrote the book, 'Change 101: A Practical Guide to Creating Change in Life or Therapy' to satisfy the dual requirements of finding a hopeful view of the possibilities of change and providing guidance in effective methods of creating change. COMOIRA, too, provides the means to investigate and intervene to facilitate change, centred upon: the ways in which that change is construed by those involved with it; the systems affecting change and in which the change must take place; the relationship factors and ways of interacting that will affect the chances of change happening at all; and the context of psychological theory and research.

Billington (2006) writes that "...in the future, it is suggested that good professional practice will demand that the practitioner is also a researcher..." (p.12), and the central core of COMOIRA reflects this vital aspect within 'Reasoned Action, Informed by Psychology', with its explicit direction to base action for change on psychological theory and up-to-date, relevant research in psychology. The social constructionism within the core of COMOIRA provides a backdrop against which any research should be evaluated, in terms of the social context within which it was carried out. 


\section{Important considerations in providing illustrations of the model in use}

The authors are keen to provide more general 'illustrations' of COMOIRA in use, rather than a limited set of 'worked examples', in order not to 'fix' or 'freeze' COMOIRA, given the two principles described below which underlie its use and development.

\section{The model is in gradual but constant development}

The first COMOIRA paper proposed '.... a new flexible model of professional practice designed to integrate theory and practice...' (Gameson et al., 2003, p.96) and the model has been used in recent years to guide the fieldwork carried out by numerous cohorts of trainee educational psychologists on the MSc and DEdPsy training programmes at Cardiff University, during their supervised fieldwork placements in local authority EPSs.

COMOIRA provides a systematic and psychological approach to fieldwork on the training programme, guiding trainees in:

- $\quad$ thinking carefully about the process issues underpinning their approaches to professional practice, including informed/ethical consent and role clarification;

- $\quad$ planning and managing their fieldwork experiences;

- $\quad$ engaging in systemic thinking;

- $\quad$ remaining alert to the impact of each individual's socially constructed 'reality';

- $\quad$ engaging with people in ways that empower and enable;

- $\quad$ focusing on the process of change;

- $\quad$ making explicit the psychology they apply to their practice; 
- $\quad$ applying psychology to local and specific contexts as opposed to general or universal ones; and

- developing their skills as reflective and reflexive practitioners.

It is fair to report that trainees have used the model in their fieldwork placements with varying degrees of confidence and success. Some have become adept at navigating the decision points and returning to the core between them, whilst others appear to have worked more pragmatically, sometimes fitting the fieldwork done into the COMOIRA framework retrospectively. It can certainly be very challenging for trainees to implement a model of working that is new and unfamiliar, especially within a service context where EPs may be unfamiliar with COMOIRA or may be critical of such an approach to EP practice.

In familiarising trainees with COMOIRA, it has become evident that engagement and ownership are vitally important and it is beneficial for practitioners to adapt the model, provided that the structure remains unchanged. Helpful adaptations to date include:

- modifying the language used to describe the various decision points and the core (a version of the model adapted in this way is shown in Appendix D);

- providing separate visual representations of the various decision points and the core;

- asking service users where on the model seems the most helpful point to begin or proceed; and 
- choosing to use only one decision point in a session with a service user, rather than moving around various points on the model.

The process of using the model in a wider variety of ways on the training programme combines with the developing fluency and creativity of staff and trainees using the model in their fieldwork and research to ensure that the model is in a state of gradual but constant development.

\section{COMOIRA as heuristic}

COMOIRA is a heuristic, which the Oxford Reference Online (2008) defines as follows: 'A process, such as trial and error, for solving a problem for which no algorithm exists. A heuristic for a problem is a rule or method for approaching a solution.' As such, it enables a person to discover or learn something for her or himself. It is a 'hands-on' approach to learning. An algorithm, by contrast, may be defined as 'a precisely described routine procedure that can be applied and systematically followed through to a conclusion' and as 'a sequential set of instructions used in calculations or problem solving, such as a stepwise series of instructions with branching pathways to be followed to assist a physician in coming to a diagnosis ... or deciding on a treatment strategy.' (Oxford Reference Online, op. cit.). The series of steps can be a repetitive one.

Those starting to use COMOIRA are often keen to see worked examples of the model in action, but its very nature as a heuristic means that, each time that it is used, the starting point, pathway through the model and endpoint will always be different, depending on the context, issues and participants at that time. 


\section{Illustrations of applications of COMOIRA}

\section{Use by trainees on fieldwork placements}

There is an increasing expectation that students at both undergraduate and postgraduate levels will be able to integrate paradigms, perspectives, frameworks, models and theories within psychology. (Quality Assurance Agency, 2002, quoted in Dixon, 2005, p.15.)

As Dixon (2005) points out, the problem-solving and decision-making literature can only offer a very general description of the processes involved in integrating theory, but not specific principles or heuristics for how to do this. Within COMOIRA, psychological theory is integrated into a framework of decision points that examines and promotes change. The practitioner's chosen psychological theories are integrated in the core of the model with other essential considerations and principles - Social Constructionism, Systemic Thinking and Enabling Dialogue - that remain vital, whatever theoretical standpoint is chosen.

How does this work in practice? The Cardiff trainees are provided with forms highlighting diagrammatically one decision point or the core of the model (for an example, see Appendix A). In addition, they have copies of the set of possible questions for use at each decision point and at the core (Gameson et al., 2003). Trainees can use as many, or as few, of the decision points as they need to, and can return as many times as necessary to any decision point, always traversing the core and considering one or more of the four key elements, on the appropriate form. Over time, the forms have been simplified 
and the most recent one allows any key decision points, and/or any aspect of the core, to be recorded on the same form (Appendix B shows a personalised version).

Stringer et al. (2006) wrote of 'Invisible Psychology', which they defined as “...the elements of our practice as applied psychologists that tend not to get noticed" (p.7). They suggest that, over time, educational psychologists may begin to fail to see what their distinctive contribution is and may well cease to reflect openly on "...what it is that they are doing that constitutes practising psychology" (p.8). One of the three ways in which psychology can be invisible, according to Stringer et al., is when it is invisible to applied psychologists themselves. Returning to the core of COMOIRA between decision points is one way of making the psychology involved much more central to the process. The distinctive contribution of an educational psychologist in applying psychology is made apparent at every step, using the COMOIRA forms. Trainees at Cardiff have used, and continue to use, COMOIRA to inform and guide their fieldwork with individuals, groups, systems and/or organisations, in many different contexts and in relation to a variety of issues and concerns. Even in their first EPS placement, trainees have used the model to guide work with, for example, whole classes, with groups of school staff and with challenging adolescents. Their chosen approaches, based on behaviour management, solution oriented thinking and investigating personal constructs, have all been incorporated into their varying uses of COMOIRA. 


\section{For personal change and development}

One of the key aspects of COMOIRA is its emphasis on reflective and reflexive uses of psychology to facilitate change. The context of EP training has been one that has seen, for several years, a high level of externallyimposed change and uncertainty in terms of funding and future role. When faced with continuing unpredictability, one of the authors has found it helpful to use COMOIRA in reflecting more systematically and dispassionately on the possible constructions amongst key stakeholders of the status of EPs and their profession; in considering the key challenges and change issues for a profession that appears to be under threat; in thinking about the intention and ability of the profession to adapt and change; and in promoting positive constructions of the possible future role of the EP amongst current trainees. For example, EPs can be reconstructed from 'a group under threat' to 'a group with a unique blend of professional, research and group process skills that can adapt to, and profit from, changing circumstances'.

COMOIRA has also been used in reflecting on the process of supervision sessions with trainees, using the Professional Supervision Form (Appendix C), particularly focusing on reviewing the process and on facilitating change (in this case, promoting a greater variety of uses of the supervision sessions). Challenging trainees' constructions of supervision as 'time to ask pragmatic questions about my next assignment' or as 'not really necessary unless something is not working out well for me' has been one outcome of these post-supervision, COMOIRA-based reflections. 


\section{In supervising trainees}

In individual supervision sessions, Cardiff trainees, their professional tutors and their fieldwork supervisors (when on placement in local authority EP services) have copies of a Professional Supervision Form which gives space for notes on the core and on each decision point. Trainees fill in the form during the supervision session and both trainee and supervisor keep a jointly signed copy.

The core of the model guides both supervisor and supervisee to be aware of the different systems - political, economic, managerial and ethical - within which supervision occurs.

The core also draws attention to the various constructions of supervision as, for example, an expensive luxury or an essential right; as an activity in which the supervisee engages only when 'stuck' or as a timetabled part of everyday practice; as a process in which the supervisee develops from 'novice' to 'master craftsman/woman'; or as a process in which the supervisor provides 'the answer' to complex or challenging problems in a 'top-down' process of giving advice. The constructions of the supervisor and the supervisee, plus their co-constructed version of the process in which they are engaging, will determine the progress and outcomes of the supervision that occurs.

Enabling dialogue, with a clear shared view of the functions and boundaries of supervision, builds a trusting relationship in which trainees, and their supervisors, can feel free and safe to disclose difficulties and dilemmas.

The supervisor's vision of the process will reflect her/his favoured psychological theory, which may be implicit rather than explicit. Presenting a 
trainee from the outset, for example, with very complex and challenging work, or conversely, with unchallenging issues, can reflect the supervisor's implicit theory of learning ('the school of hard knocks' or 'you can't run before you can walk').

\section{In work with service users}

a. As a general aid. All EPs will have built up a collection of favoured techniques and approaches for use in consultations and interventions, and it has been useful to one of the authors to organise such devices into an 'aide memoir', based on COMOIRA. The table below shows only a selection of the decision points and the ideas/materials relating to them. The materials chosen for inclusion, and the approaches favoured, cannot but reflect the personal interests of the author, including cognitive behavioural and solution oriented approaches; a focus on explaining, investigating and promoting change with service users; and experience of what has worked in the past and what service users have found most helpful.

Table 1 - Example of contents of a personalised COMOIRA handbook

\begin{tabular}{|l|l|}
\hline \multicolumn{1}{|c|}{ Decision Points } & \multicolumn{1}{c|}{ Materials } \\
\hline $\begin{array}{l}\text { Construct and Clarify } \\
\text { Key Change Issues }\end{array}$ & $\begin{array}{l}\text { A simplified version of the model of change proposed by Prochaska et } \\
\text { al. (1994), described in Carr (2004, p.303). } \\
\text { A decision tree diagram, to identify priorities for action. } \\
\text { An aide memoir for the EP, listing techniques for eliciting information, } \\
\text { including scaling (with or without 'smiley faces', depending on the age } \\
\text { of the service user), drawing, self description, narrative questions, } \\
\text { PCP techniques and published questionnaires e.g., the Self Image } \\
\text { Profiles (Butler, 2001). }\end{array}$ \\
\hline \begin{tabular}{l} 
Explore $\begin{array}{l}\text { Constructions of } \\
\text { Ability to Change } \\
\text { and Intention to } \\
\text { Change }\end{array}$ \\
\hline
\end{tabular} & $\begin{array}{l}\text { A prompt list for the EP - factors to explore re: change - willingness, } \\
\text { likelihood (self prediction), readiness, determination, desire, strength, } \\
\text { ability and confidence. }\end{array}$ \\
\hline
\end{tabular}




\begin{tabular}{|l|l|}
\hline Facilitating Change & $\begin{array}{l}\text { Checklist for monitoring and challenging unhelpful thinking about } \\
\text { change. } \\
\text { Checklist from Carr (2004, p.309) adapted from Prochaska et al. } \\
\text { (1994), which assesses the pros and cons of changing and rates the } \\
\text { likelihood of progressing to action (a total pros score of } 28 \text { and a total } \\
\text { cons score below 17 is needed). } \\
\text { A simpler form, listing the pros and cons of changing or staying the } \\
\text { same for that individual in a 4x4 grid, giving a more personal version } \\
\text { of the Carr (2004) checklist. } \\
\text { Outline of the stages to expect, following change (positive or negative) } \\
\text { - from immobilisation to internalisation. } \\
\text { Checklist - Factors associated with resilience in adolescence, from } \\
\text { Carr (2004, p.271). }\end{array}$ \\
\hline $\begin{array}{l}\text { Construct and } \\
\text { Explore Relevant } \\
\text { Hypotheses }\end{array}$ & $\begin{array}{l}\text { Form to collect from each person: } \\
\text { a. ideas on why the problem has arisen; } \\
\text { b. ideas on what is maintaining the problem; and } \\
\text { c. ideas on what could help to create change. }\end{array}$ \\
\hline
\end{tabular}

\section{b. In work with organisations}

This section will outline the use of COMOIRA with two separate EPSs, in both a training context (using the model to explore a hypothetical issue) and in the context of a service wishing to explore adopting COMOIRA as its service practice model.

\section{Educational Psychology Service 1}

The basic framework of COMOIRA was introduced to one EPS on a training day and the model was then used in a simulation of a service responding to an issue that was becoming common within local authorities - the implications for the role of EPSs and EPs of the development of Children's Services.

The EPs, working in small groups, considered the challenges within this scenario in the following sequence: 
- Social Constructionism - looking at, for example, the constructions of the EP role and the unique skills of the EP amongst other professionals within a Children's Service;

- Systemic issues - considering links with other services, pressures on the EPS as a system, boundaries and feedback loops;

- Enabling Dialogue - discussing who needs to be involved, and how, in ensuring EPs are able to contribute as successfully as possible their unique skills in the context of a Children's Service;

- Informed, Reasoned Action based on Psychology - making explicit the aspects of psychology that could be helpful in thinking about the formation of new teams; the identity of EPs within these teams; and the preferred futures for the EPS;

- A decision point chosen by each group individually - depending on the services/service users identified in the two previous points, groups were encouraged to explore approaches to engagement, which might include improvisation of particular scenarios;

- Repeat of the activity, but using a different decision point; and

- Review the process of using COMOIRA in this way, with this issue.

Feedback from the EPS indicated that the notable aspects of the model were that:

- it focuses on the application of psychology in a collaborative process;

- it emphasises the process of change;

- it moves away from linearity to dynamic flexibility; 
- it involves a reminder to find out other peoples' constructions, needs, wants, etc., in order to achieve a shared meaning;

- it encourages practitioners to apply psychology to themselves; and

- 'it feels quite comfortable'.

Challenging and exciting issues were:

- the worry associated with moving from unconscious incompetence to conscious incompetence;

- keeping the psychology explicit;

- creating an agreed construction of what is going on;

- keeping an open mind and listening to other peoples' versions of events;

- time issues e.g. spending enough time on the various parts of the process;

- remaining with the process when working with professionals from other agencies; and

- being explicit about what people should expect from the EP.

\section{Educational Psychology Service 2}

COMOIRA had already been introduced to an EPS team that was considering adopting it as the service's practice model and programme staff had agreed to return to follow up the work done in the initial session. The process in the follow up session proceeded as indicated in Table 2 below. The EPS team 
worked as a whole group and the only equipment used was a poster showing

the COMOIRA model, plus a flip chart for recording responses.

Table 2 - Summary of activities in using COMOIRA with EPS 2

\begin{tabular}{|c|c|}
\hline Aspects of COMOIRA & Activities \\
\hline $\begin{array}{l}\text { Core - Social } \\
\text { Constructionism }\end{array}$ & $\begin{array}{l}\text { Exploring team members' constructions of COMOIRA - collecting } \\
\text { three adjectives from each EP. }\end{array}$ \\
\hline Reviewing the Process & $\begin{array}{l}\text { Using a rating scale to check and reach a shared understanding of } \\
\text { part of the process so far. How much each individual and the team } \\
\text { had managed to use COMOIRA. Rating }(1=\text { not very much to } 10= \\
\text { a great deal). }\end{array}$ \\
\hline $\begin{array}{l}\text { Core - Social } \\
\text { Constructionism and } \\
\text { Systems Theory }\end{array}$ & $\begin{array}{l}\text { Additional constructions of the value of the model were sought. } \\
\text { Systemic issues were explored. }\end{array}$ \\
\hline $\begin{array}{l}\text { Core - Enabling } \\
\text { Dialogue }\end{array}$ & $\begin{array}{l}\text { EPs were asked who in the system would need to be involved, } \\
\text { through enabling dialogue, in the process of moving to using } \\
\text { COMOIRA. }\end{array}$ \\
\hline $\begin{array}{l}\text { Core - Relevant } \\
\text { Psychology }\end{array}$ & $\begin{array}{l}\text { EPs were asked to identify any relevant psychology that could help } \\
\text { to explain the issues that had kept the team from using COMOIRA. }\end{array}$ \\
\hline $\begin{array}{l}\text { Core - Systems } \\
\text { Theory }\end{array}$ & $\begin{array}{l}\text { Some key ideas from systems thinking were outlined, e.g., } \\
\text { symptomatic/reactive vs. fundamental/strategic change, plus } \\
\text { feedback loops. }\end{array}$ \\
\hline $\begin{array}{l}\text { Construct and Explore } \\
\text { Relevant Hypotheses }\end{array}$ & $\begin{array}{l}\text { EPs were asked for their own hypotheses to explain why the service } \\
\text { had not taken on COMOIRA, plus what they thought others' } \\
\text { hypotheses about the issue might be. }\end{array}$ \\
\hline $\begin{array}{l}\text { Core - Relevant } \\
\text { Psychology }\end{array}$ & $\begin{array}{l}\text { EPs were asked to identify the psychology relating to the } \\
\text { hypotheses they had generated. }\end{array}$ \\
\hline $\begin{array}{l}\text { Construct and Clarify } \\
\text { Key Change Issues }\end{array}$ & $\begin{array}{l}\text { EPs were asked to suggest what might need to change in several } \\
\text { contexts, in order for COMOIRA to be adopted by the team. }\end{array}$ \\
\hline $\begin{array}{l}\text { Core - Relevant } \\
\text { Psychology }\end{array}$ & $\begin{array}{l}\text { It was important to make sense of the process of change, including } \\
\text { highlighting the difficulty level of the activities at the various stages } \\
\text { of the Prochaska et al. (1994) model, i.e., that making a change and } \\
\text { keeping it going were likely to be harder than making decisions } \\
\text { about changing. }\end{array}$ \\
\hline $\begin{array}{l}\text { Investigating Intention } \\
\text { to Change }\end{array}$ & $\begin{array}{l}\text { EPs were asked to rate their intention to change their practice in } \\
\text { order to use COMOIRA (using a scale with } 1=\text { very weak intention } \\
\text { and } 10=\text { very strong intention to change). }\end{array}$ \\
\hline
\end{tabular}


This process occupied all of the time available during the session. If there had been more time, the next steps might have been to explore the 'Ability to Change', 'Review the Process' or 'Facilitate Change' decision points.

Informal feedback from the EPs indicated that they thought that the process had allowed a free and frank but calm discussion; that a wide range of issues had been raised in a relatively short space of time; and that these issues had been addressed more fluently and efficiently than might have been achieved by using less structured approaches. Despite the team's favourable response to this demonstration of the model in action, and the expectation that it would become more widely used by team members, a period of intense change in the service context has prevented this from happening, to date.

\section{Challenges to the Use of the Model}

This section will outline some of the possible perceived barriers to the use of COMOIRA, which appear to reflect limiting constructions of various types.

\section{Restricting the range of uses of the model}

The authors now consider that their previous construction of COMOIRA as a model to guide the fieldwork practice of trainee educational psychologists may, unintentionally, have limited the ways in which they and others have considered using it. Similarly, constructions of the model as 'something that only trainees use/understand', may have limited the readiness, willingness and ability of qualified EPs, even when supervising trainees in the field, to engage more actively with the model. As a result of reconstructing COMOIRA as 'a model to use in all aspects of the DEdPsy programme, sessions with trainees have been structured around key decision points and COMOIRA has 
also been used as the basis for structured reflection by trainees on the progress of their learning within each of the six programme themes, during a mid-year review for Year 1 trainees.

Members of the programme team have also reflected on the advantages and disadvantages of providing detailed and structured forms devised for recording fieldwork based on COMOIRA, since these may also have proscribed potential applications of the model. Developments of the recording forms have involved: firstly, a completely open structure for use and reporting on the model; then highly detailed and structured forms (with a separate form for the Core and each decision point) to record how the model was used for each piece of fieldwork; and, more recently, a return to a more open structure of forms with fewer headings, which can be used more flexibly by the trainee and others (as shown in Appendix B).

\section{Perceptions of the model as time-consuming}

Since trainees are required to cover a limited number of pieces of fieldwork that enable them to engage in on-going, in-depth work over time, it can be hypothesised that the model may also have been construed as 'too timeconsuming' for use by those with fuller workloads. It may be that COMOIRA challenges constructions of the way in which fieldwork should be approached, for example, by pragmatically following custom and practice or habit, by working within pre-determined and non-negotiable time limits, or even by setting out with a fixed end in mind.

However, COMOIRA might still be helpful within these contexts because no lower limit is set on the number of decision points to be used, or on the 
number of times the Core of the model should be visited, in any piece of work, so, in practice, it is possible to use only one or two decision points. For example, using only 'Construct and Clarify Key Change Issues' and 'Facilitate Change' would fit well with solution oriented approaches. Scaling and the Miracle Question could be used to construct the key change issues, and the core element of reasoned action, informed by psychology (from knowledge of solution oriented principles) would determine how change could be promoted. Within the solution oriented approach, this could well be via homework exercises, with the service user 'doing more of what works', and/or the use of therapeutic letters by the EP.

It could be argued that, during the initial stages of developing new skills and competencies, for example, when working with a new model such as COMOIRA, a practitioner would move through the stages of unconscious incompetence, conscious incompetence, conscious competence and unconscious competence towards reflective competence (businessballs.com 2008). At the stage of conscious competence, for example, a practitioner would naturally use a new model more slowly and deliberately than during the later, unconscious and reflective stages of competence, when practice has enabled more fluent and seamless movement around the model. In this respect, learning to use COMOIRA is no different from learning to use any other model or acquiring any other new skill. Practitioners who are not ready, willing and able to engage actively in these challenging and often uncomfortable processes might not persevere long enough to facilitate changes to their established ways of working. It could be argued that professional practice that is not underpinned by an explicit and coherent 
theoretical model can only result in less effective work, in which the psychology is invisible to the practitioner, as well as to the service user.

The core element of reasoned action informed by psychology also ensures that the EP always brings at least three distinctive features to any work: knowledge of the context, for example, particular stages of the education system or of the developmental challenges at particular stages in childhood and adolescence; a psychological viewpoint; and the ability to apply and interpret research methodology. The current climate is one in which there has been a recent study of stakeholders' views about "...the distinctive contribution that EPs can make in the newly established children's services..." (Farrell et al., 2006, p.1). One of the findings of this study was that "It was the view of a significant proportion of stakeholders that an alternative provider might, in some circumstances, have been able to carry out some aspects of the work that an EP might currently carry out (p.1) and it seems critical, therefore, to be able to demonstrate the distinguishing aspects of EP practice, already listed above, through using a model such as COMOIRA, which makes them explicit.

\section{Constructions of the model as 'too complex' or 'too difficult'}

Although these are likely to be based on inaccurate or misguided assumptions about the possible ways of engaging with COMOIRA, such constructions will inevitably lead to a lack of willingness to engage with it. Yet, it is now clear that other models used in EP practice over the last forty years were also complex when first introduced; that many activities, both professional and everyday, are based on complex sets of co-ordinated actions and skills (for example, driving a car and using a computer) that are mastered with practice; and that feelings of conscious incompetence arise inevitably in the early 
stages of acquiring any new skill. However, it may be that those seeking predictability will be challenged significantly by models that do not offer a linear sequence of steps to guide actions and also by those which do not include detailed, worked examples of the model or activity in practice. These issues are discussed in more detail below.

Kelly (2006), in an article exploring the usefulness of the Monsen Problemsolving Framework for Applied Practitioners, offers the following assertion regarding COMOIRA:

Arguably, from the point of view of the practitioner, this is an unnecessary and in many ways unhelpful attempt to combine meta modelling with complex, psychological and systemic theory in one dynamic model. Such a model seems to hold less immediate relevance for stakeholders. (p.11)

The views of stakeholders and also of those with experience of using the model in educational psychology practice, for example, the Cardiff trainees, will be vital in illuminating whether or not there is any evidence to support this assertion. Recent developments in sharing the structure of the model with teachers and pupils have shown that, with suitably adapted language, and sometimes making use of simpler visual representations of COMOIRA, it can inform both the service user and the EP.

\section{Attributing agency and challenges to the model itself, rather than to} the way in which the practitioner chooses to relate to the model

Attributions that do not conceptualise the model as a tool, but instead endow it with its own life and characteristics, may deter practitioners from starting to 
use COMOIRA, or from using it flexibly or 'experimentally', with the model serving the user's chosen purpose and acting as an aid to creativity rather than a brake.

It may be helpful to refer here to O'Hanlon (2006), who, when discussing solution focused work, offers the sailor's maxim that "You can't steer a ship until it is moving." (p.153). He suggests that "...you can always make course corrections once you begin, if you see you are heading in the wrong direction." (p.153). During a recent supervision development session for EPs, which involved practice in using COMOIRA, this 'course correction technique' was applied, by stopping a supervision role play at certain points and re-starting it at a completely different point in the model. This demonstrated that, although different 'courses' generate different outcomes, there are no correct or incorrect, best or worst starting points when using this model.

As a result of reconstructing and widening the possible applications of the model, much of the professional supervision for trainees on the Cardiff DEdPsy programme since 2006 has been carried out using COMOIRA. Some Fieldwork Supervisors have also used the model as their basis for supervising trainees. The model is relevant to all types of supervision, since supervision in its widest sense is a process involving change and development for all those involved in the activity.

More experimental approaches have seen it used by individuals to promote personal change and development, and also in consultation with a whole EPS team. 


\section{The desire for worked examples}

Trainees and qualified EPs who are new to COMOIRA often ask for 'worked examples' to follow before using the model in their own practice and it may be that some initial anxiety about tackling fieldwork leads trainees to look for a 'how-to' list. Billington (2006) asserts, in the introduction to his book 'Working with Children', that 'Those readers who prefer unproblematic accounts of issues and dilemmas....are likely to be disappointed here." (p.4). Similarly, the authors of this paper do not wish to give the impression that there is a single, simple, 'best' way to use COMOIRA.

Since writing Part 2 (Gameson et al., 2005), the authors have come to think differently about the interesting, challenging and complex idea of providing selected, detailed worked examples of the model in practice, especially within the context of a relatively short, static published paper. It is arguable that the use of 'worked examples' or 'ideal versions' of COMOIRA in action might serve to 'fix' COMOIRA or position it in ways that undermine its flexibility. It seems important to question the assumption that worked examples are necessarily helpful in the longer term; or essential to the process of disseminating a new model; or vital to promoting new learning and/or new approaches to practice. This position is consistent with the principles underpinning some models of adult learning, for example, Problem-Based Learning (Chernobilski, Dacosta and Hmelo-Silver, 2004), which are not based on the idea of preconceived and/or right/wrong procedures, approaches or outcomes etc. The position is also consistent with a fundamental principle underpinning COMOIRA, namely, the importance of 
enabling and empowering individuals, and avoiding dependence on an expert or on 'established' views of events.

It is important for trainees and practitioners to have confidence in, and build on, the skills they have already developed, adapting and personalising their uses of COMOIRA in ways that are innovative and creative, rather than predictable or imitative.

The decision not to include detailed written worked examples is intended to be 'challenging' and 'liberating' rather than 'unhelpful' to the reader. It arises from a carefully considered position and not from an unwillingness to share practice with others or from wanting to be difficult, unhelpful, secretive, defensive or simply just different. It will be more appropriate to share and explore worked examples of the model in practice possibly within the context of CPD sessions, conference presentations and seminars, when there will be opportunities for dialogue and for details to be explored.

\section{The way forward - working with COMOIRA}

Becoming adept at using any technique demands practice and perseverance.

It has become increasingly apparent that those using COMOIRA need to:

1. engage actively in the process of exploring possible applications of the model (as opposed to copying some existing example of its use);

2. adapt the formal language of the model to suit the service users they work with, but also to reflect their own personal style of expression (for example, using 'What's your idea about why this is happening?' for 'Construct and Explore Relevant Hypotheses), as shown in Appendix D; 
3. present the model in a way that is appropriate for the service user (for example, using and looking at only one decision point, if presenting the entire model, even with its language altered appropriately, might be overwhelming, confusing and/or off-putting);

4. use materials or techniques that have been found to be helpful in the past, which could range from narrative techniques or drawing to using published tests or doing a Rep Grid, amongst other possibilities);

5. use explicitly whatever psychology they know and have found to be useful and appropriate, at the core of the process, between decision points. One theory is not more valuable than another, and applying one theory in depth is not somehow less desirable than using a wide range of theories.

However, it may be important to learn more about the research taking place in areas of psychology outside education. For example, examining the factors that have been found to influence the completion of a course of medication could well help educational psychologists who are encouraging students to put intentions to behave differently into practice in the longer term (the 'Maintenance' stage in the change model proposed by Prochaska, DiClemente and Norcross, 1994, as described in Carr, 2004); and

6. accept that, since no two situations are identical, but encompass different service users, different problem situations, different professional groups and different theoretical perspectives, each situation might warrant, and result in, a different starting point; a different path through the stages of the model; and a different combination of elements of the model. 
It is essential for practitioners who use COMOIRA to adapt and 'personalise' the model in order to make it most accessible to service users and to make best use of each individual practitioner's personal style and theory base. It is important, however, that such adaptations should not lead to key features (e.g., the focus on change in each of the decision points, plus the central concepts of social constructionism and systemic thinking) being lost or abandoned.

The authors continue to use COMOIRA to inform and guide their professional practice in the field and in supervising trainees. COMOIRA is also now being used to inform and guide many aspects of the Cardiff DEdPsy Initial Professional Training Programme, including the delivery of the curriculum within university-based teaching sessions, trainees' fieldwork activities and CPD activities, especially those that focus on the development of supervision skills for qualified EPs.

The next stage in the development of the model will be a process of systematically researching:

a) the extent to which qualified EPs, who might not be familiar with COMOIRA, value and make use of key aspects of the change processes that make up the model, in their professional practice. This could involve asking questions such as 'How important is it to you to ask if service users are ready to change?';

b) the extent to which COMOIRA-based training has impacted on the practice of recent graduates from the Cardiff MSc and DEdPsy initial training programmes; 
c) what would need to change in order for ex-Cardiff trainees and serving EPs to use COMOIRA more in their day to day work (i.e., investigating the key change issues); and

d) EPs' constructed hypotheses about the reasons for not adopting COMOIRA in aspects of their practice.

Over time, it has become apparent that possible applications of COMOIRA are limited only by users' selective constructions of when it is appropriate to use the model. By altering these constructions, it is possible to widen its use into many more areas of EP practice and training. 


\section{References}

Billington, T. (2006). Working with Children. London: Sage Publications. Boyle, J. M. E., \& MacKay, J. (2007). Evidence for the efficacy of systemic models of practice from a cross-sectional survey of schools' satisfaction with their educational psychologists. Educational Psychology in Practice, 23(1), 19-31.

Butler, R. J. (2001). Self Image Profiles (SIP). Oxford: Harcourt Assessment. Businessballs.com (2008). The Conscious Competence Learning Model. Accessed 03.12.08. at http://www.businessballs.com/consciouscompetencelearningmodel. htm

Carr, A. (2004). Positive Psychology: The Science of Happiness and Human Strengths. Hove, East Sussex: Brunner-Routledge.

Chernobilsky, E., Dacosta, M.C. \& Hmelo-Silver, C.E. (2004). Learning to talk the educational psychology talk through a problem based course.

Instructional Science, 32, 4, 319-356.

Dixon, R. (2005). Integrative Thinking: building personal, working models of psychology that support problem-solving. Psychology Learning and Teaching, 5(1), 15-22.

Farrell, P., Woods, K., Lewis, S., Rooney, S., Squires, G. and O'Connor, M. (2006). A Review of the Functions and Contribution of Educational Psychologists in England and Wales in light of "Every Child Matters: Change for Children". Research Report No. 792. London: DfES. 
Gameson, J., Rhydderch, G., Ellis, D. and Carroll, H.C.M. (2003).

Constructing a flexible model of integrated professional practice: part 1, conceptual and theoretical issues. Educational and Child Psychology, 20(4), 96-115.

Gameson, J., Rhydderch, G., Ellis, D. and Carroll, H.C.M. (2005).

Constructing a flexible model of integrated professional practice: part 2, process and practice issues. Educational and Child Psychology, 22(4), 4155.

Hultman, K. (1998). Making Change Irresistible: Overcoming Resistance to Change in Your Organisation. Palo Alto, California: Davies-Black Publishing.

Kelly, B. (2006). Exploring the usefulness of the Monsen Problem-solving Framework for applied practitioners. Educational Psychology in Practice, 22(1), 1-18.

O’Hanlon, W.H. (2006). Change 101: A Practical Guide to Creating Change in Life or Therapy. London: W.W. Norton.

Oxford Reference Online (2008). Search for Heuristic and Algorithm. Accessed 03.12.08. at

http://www.oxfordreference.com/views/GLOBAL.html?authstatuscode=202

Prochaska, J., Norcross, J., and DiClemente, C. (1994). Changing for Good. New York: Avon.

Quality Assurance Agency. (2002). Psychology: Subject Benchmark Statements. Gloucester: Quality Assurance Agency for Higher Education. 
Stringer, P., Brewin, A., Duggan, A., Gessler, B., \& Low Ying, J. (2006). The curious practice of invisible psychology. Division of Educational and Child Psychology, Debate, 121, December, 7-11. 


\section{Appendix A - COMOIRA Recording Sheet used by Cardiff Trainees}

\section{A Constructionist Model of Informed, Reasoned Action (COMOIRA)}

(Applying Psychology to the Process of Change)

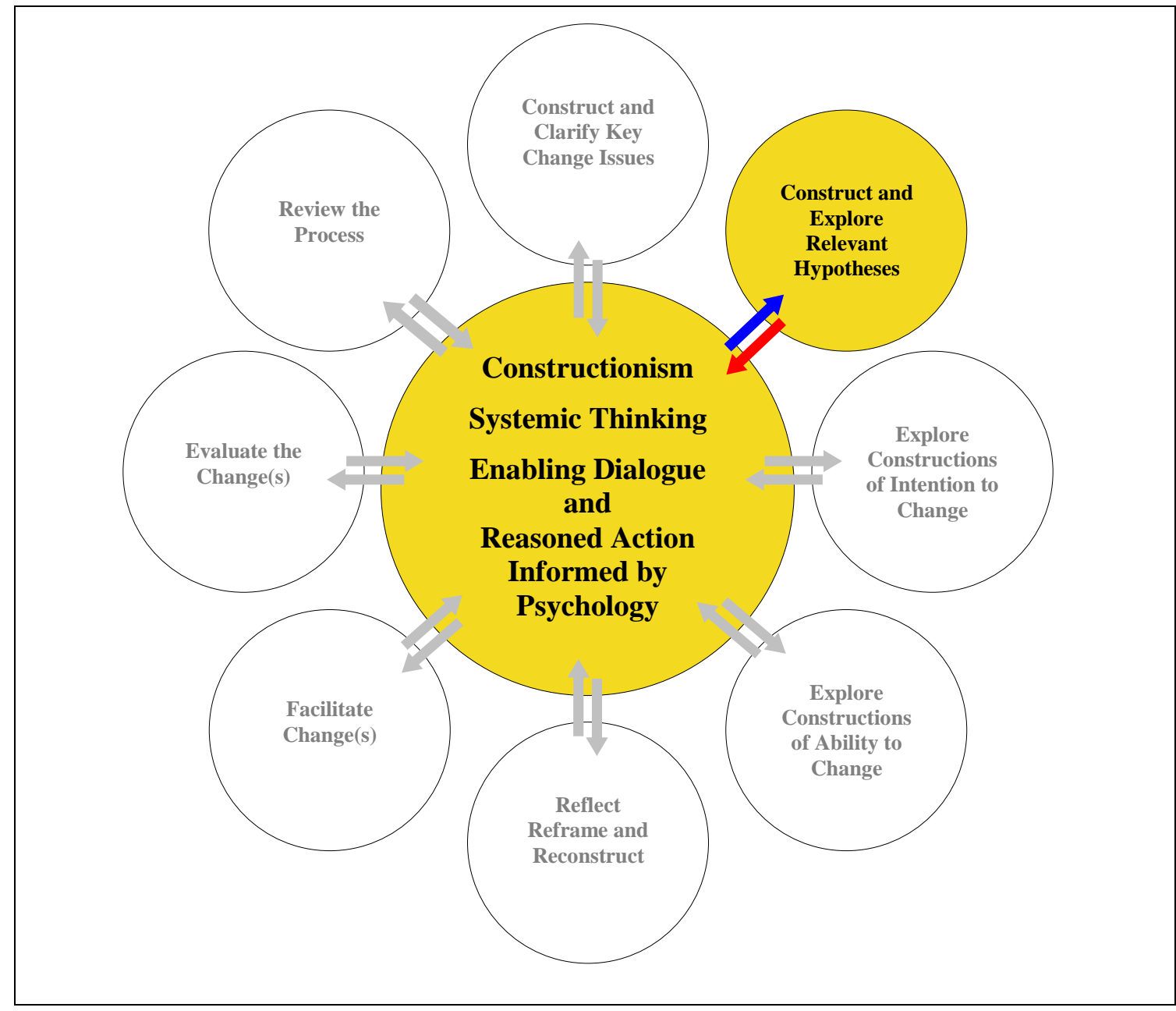

\section{Construct and Explore Relevant Hypotheses}

The questions at this point are intended to help the practitioner and service-user(s) to explore how relevant people (these include the practitioner) construct and explore relevant hypotheses in relation to:

- factors that are causing and/or contributing to the issue or concern;

- factors that are maintaining the issue or concern; and

- what needs to be done to improve or find a solution to the issue or concern. 


\section{Construct and Explore Relevant Hypotheses}

- What hypotheses are people, including you, constructing re: factors that are causing and/or maintaining the issue(s) of concern at each point?

- At what level are people choosing to construct hypotheses (organisation, system, group and/or individual)? Why are they being constructed in these terms?

- Is it appropriate to explore/test the chosen hypotheses? If so, what, when, who, where and how etc?

- What relevant data are being constructed at the level of the organisation, system, group and/or individual (including you)?

- What data are required and at what level should they be collected? (e.g., whole organisation, system, group and/or individual (including you)?

- How will the data help to inform the constructed choices, change issues and hypotheses at each key decision point?

- What are the constructed implications regarding the questions, change issues, hypotheses and further action?

- What are the constructed implications for the systems, sub-systems, and individuals concerned (including you and your service)?

- What circular/reciprocal relationships can be constructed and how might these influence people's interpretations of the current view of events? 
Construct and Explore Relevant Hypotheses

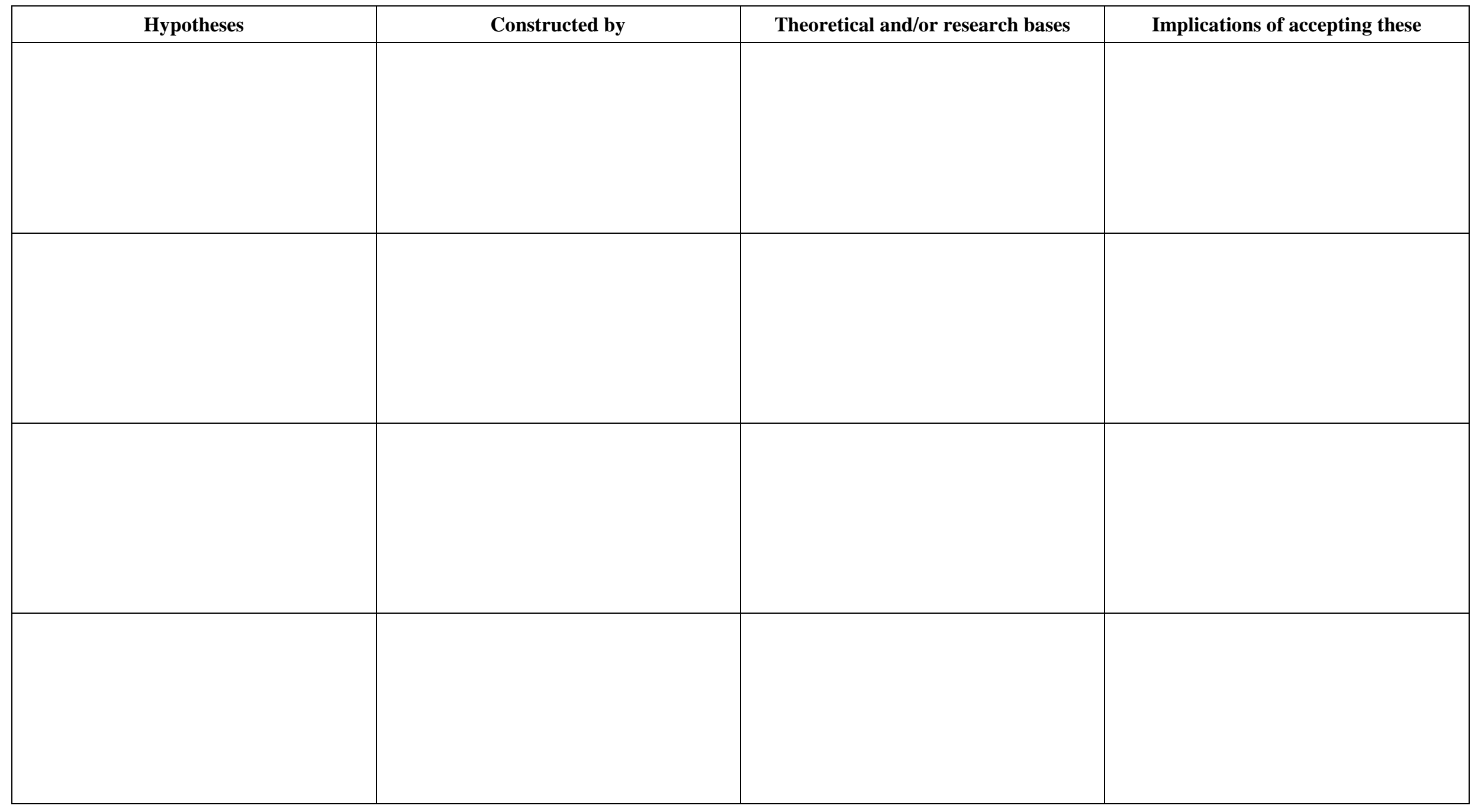


Construct and Explore Relevant Hypotheses

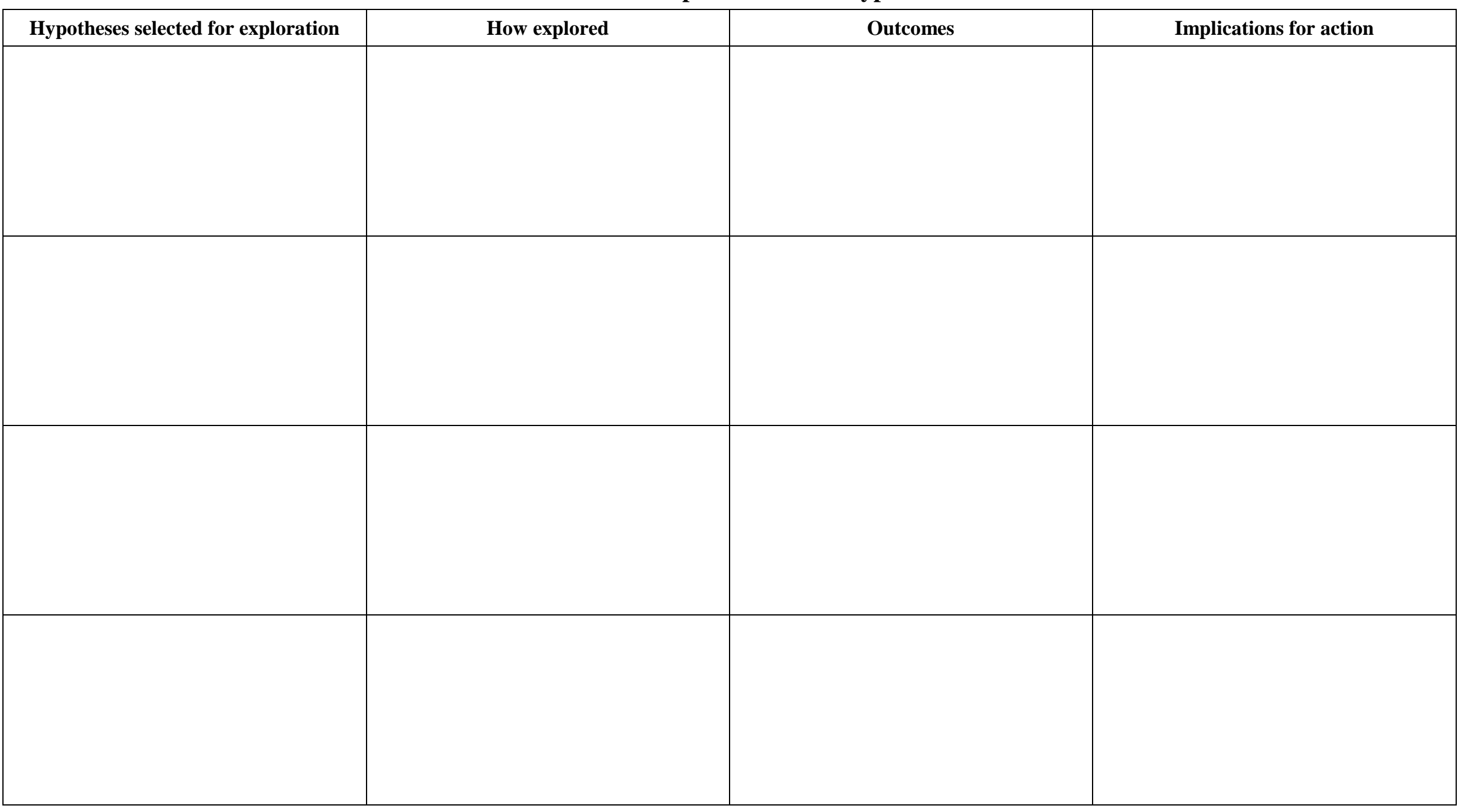


Return to the Core and Reflect on the Process and Planned Action

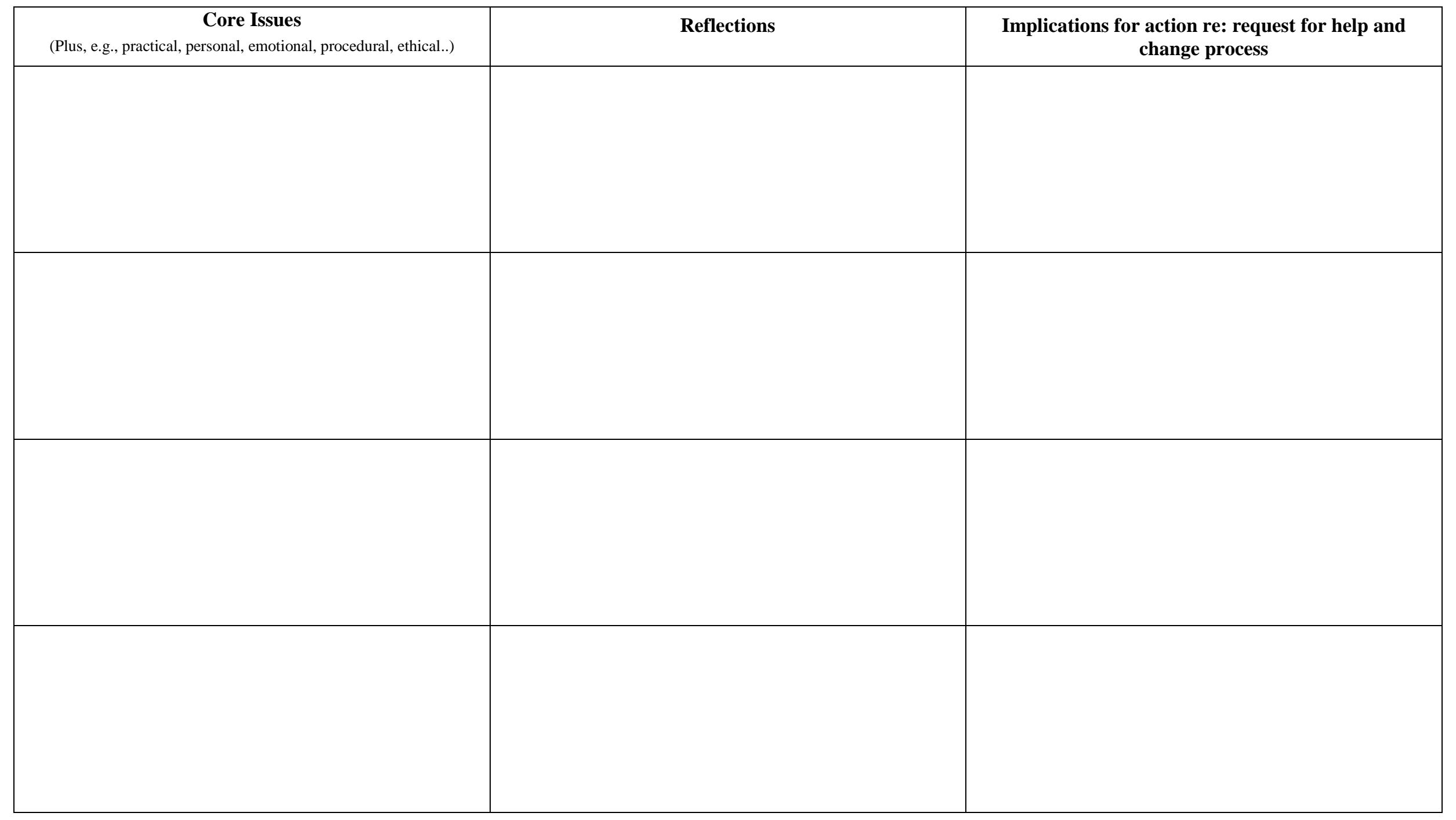


Sources of Evidence - Psychological and/or other theories and research results (including assessment outcomes)

\begin{tabular}{|l|l|l|}
\hline $\begin{array}{c}\text { Sources of evidence - theories, conceptual } \\
\text { frameworks and research results }\end{array}$ & \multicolumn{2}{c}{$\begin{array}{c}\text { How they were used to inform this stage of the } \\
\text { change process? }\end{array}$} \\
\hline & & \\
\hline & & \\
\hline & & \\
\hline & & \\
\hline
\end{tabular}

Choose which key decision/action point to move to next

\begin{tabular}{|l|l|}
\hline Key Decision/Action Point & \\
\hline & \\
& \\
\hline
\end{tabular}




\section{Appendix B - COMOIRA Record Form - Personalised}

Working Together for Positive Change

\begin{tabular}{|l|l|l|l|l|}
\hline Date & Location & Duration of contact & People engaged with on this occasion & Psychologist \\
\hline & & & & \\
\hline
\end{tabular}

\begin{tabular}{|c|c|c|}
\hline & Name(s) & Signature(s) \\
\hline $\begin{array}{l}\text { 1. I understand that } \ldots \ldots \ldots \ldots \ldots \ldots \ldots \ldots \ldots \text { is an educational psychologist } \\
\text { who works for } \ldots \ldots \ldots \ldots \ldots \ldots \ldots \ldots \ldots \ldots \ldots \ldots \ldots \ldots \ldots \ldots \ldots \ldots \ldots \\
\text {. Council. }\end{array}$ & & \\
\hline 2. I understand why we are meeting together today. & & \\
\hline 3. I am happy to take part in the session today. & & \\
\hline
\end{tabular}

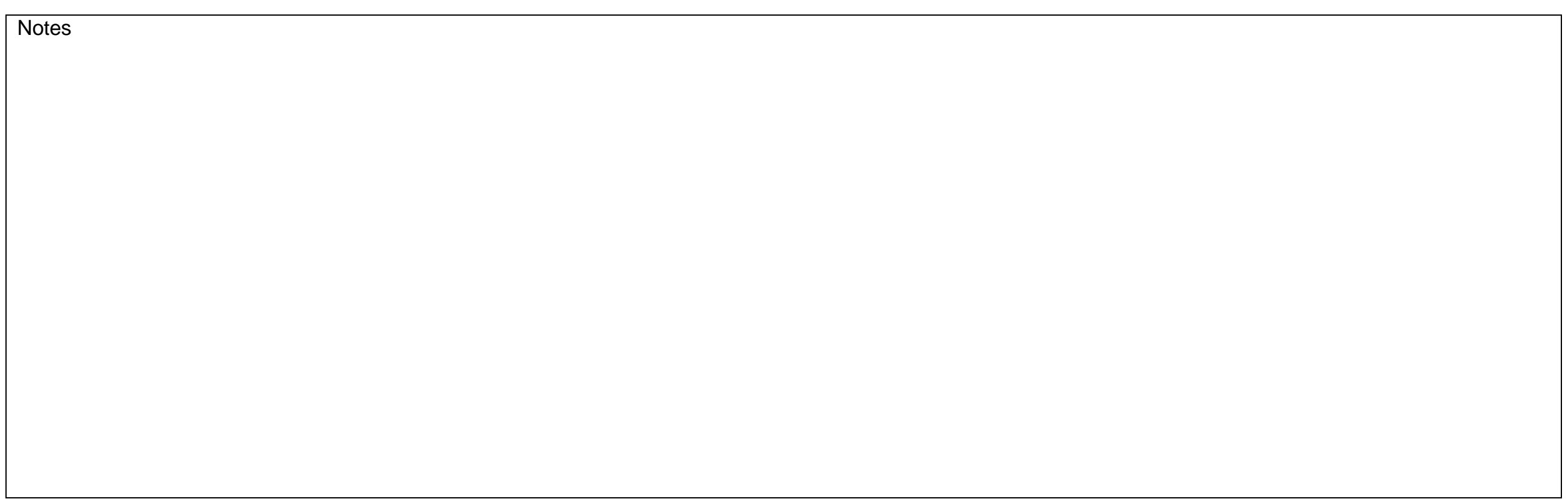




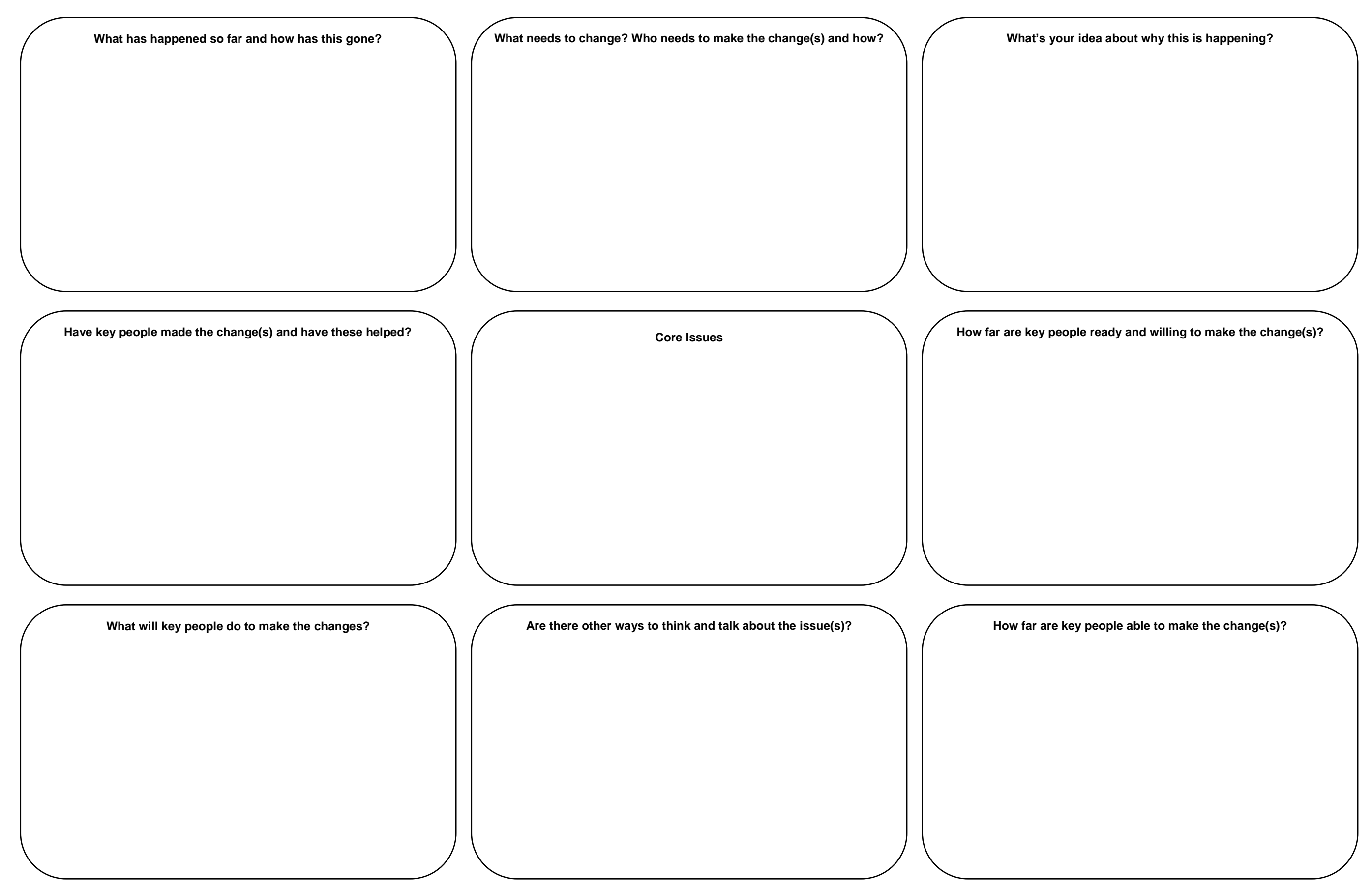


Appendix C - Professional Supervision Form

(Please use the framework overleaf in conjunction with COMOIRA)

\begin{tabular}{|l|l|l|}
\hline Date of Session & Supervisor & Trainee(s) \\
\hline & & \\
& & \\
\hline
\end{tabular}

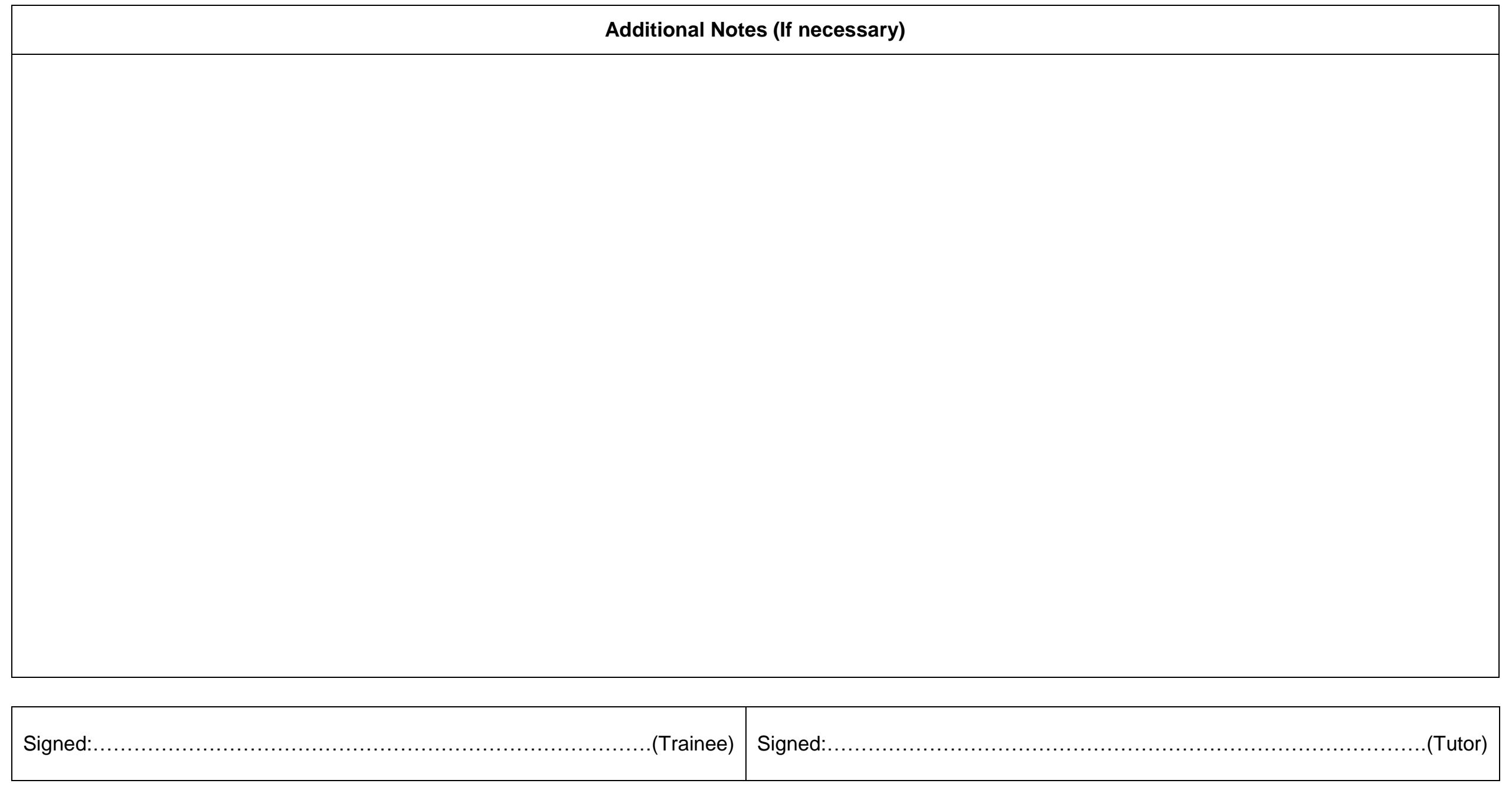




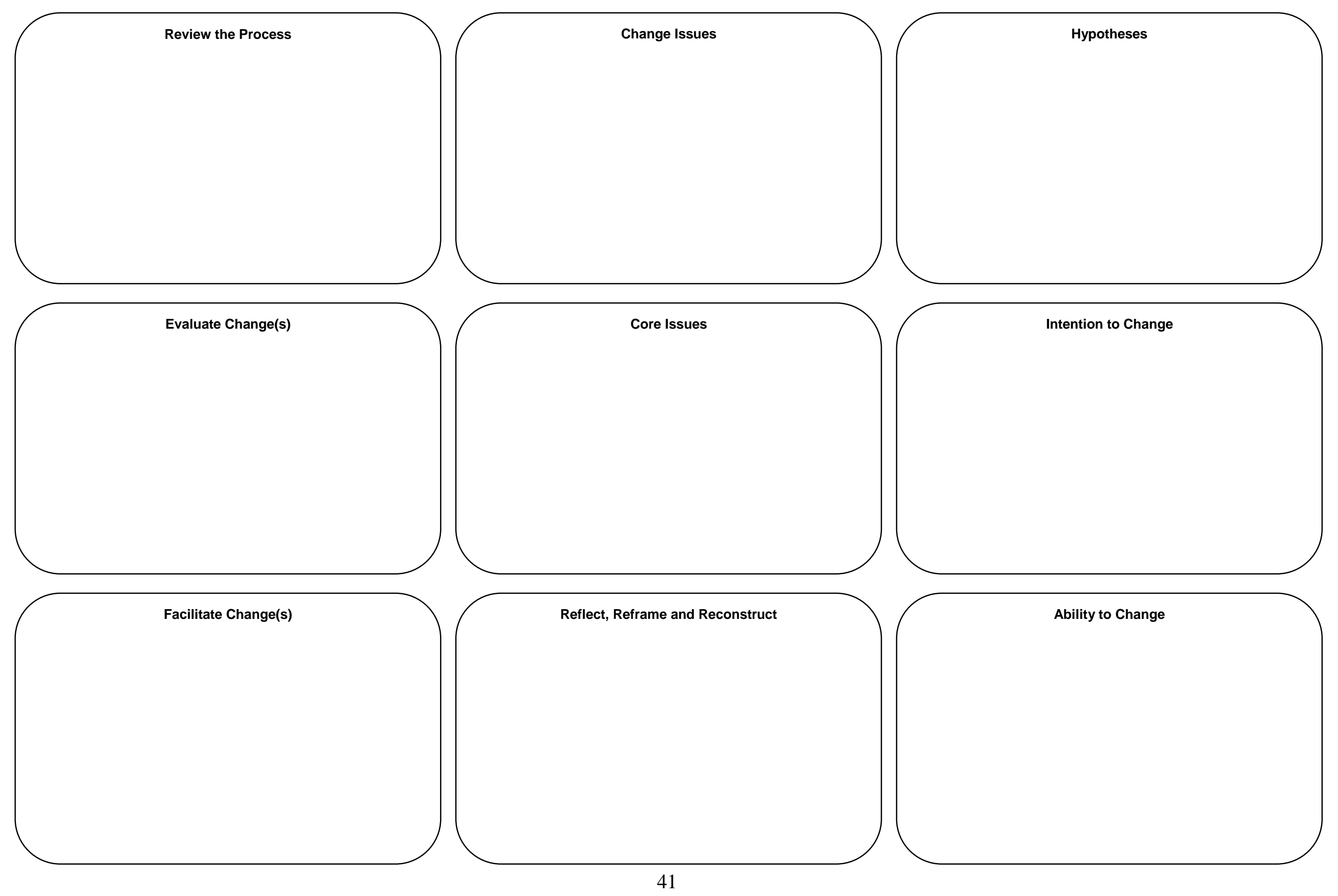




\section{Appendix D - Model with adapted language}

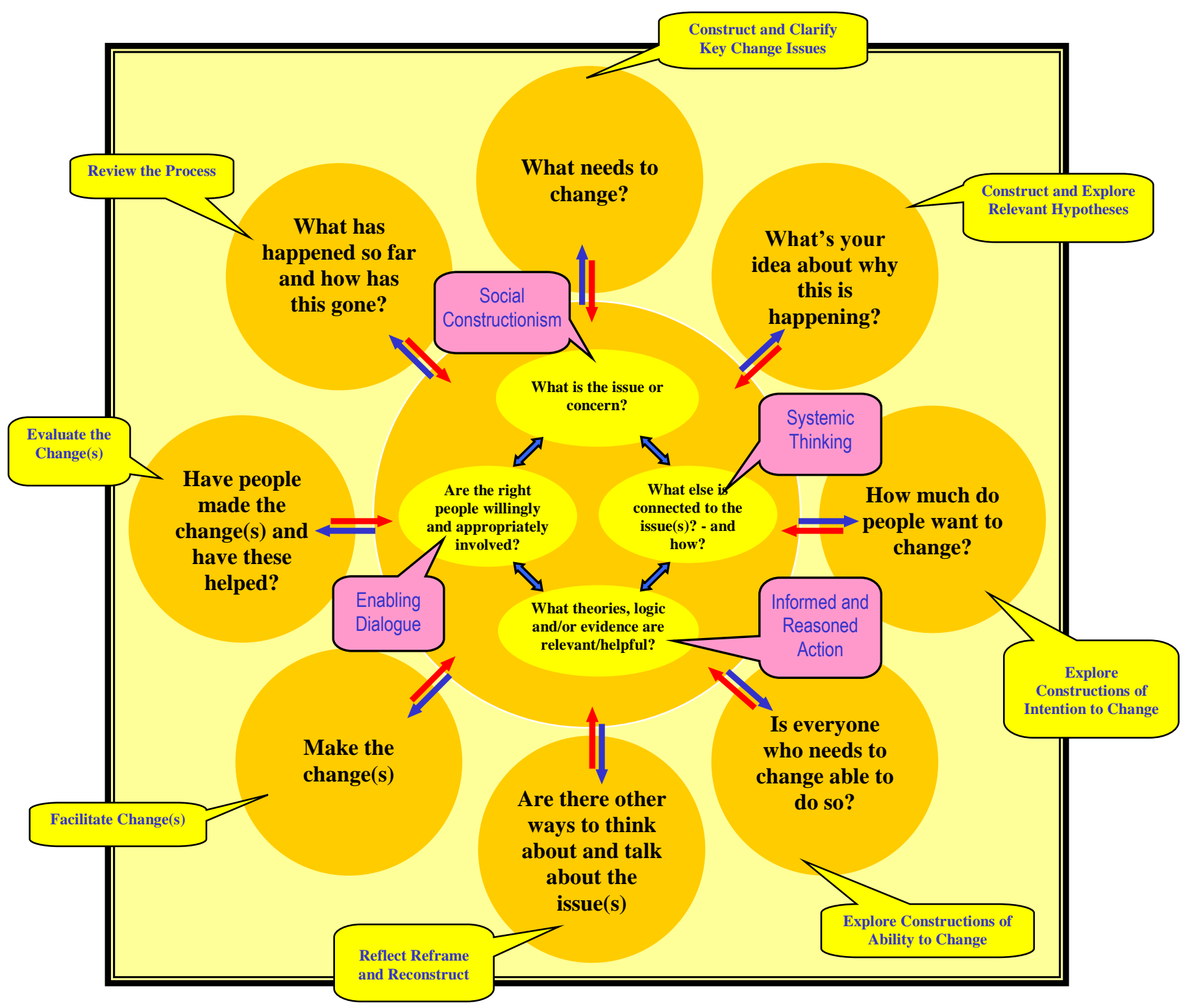

